\title{
Heel Enthesopathy of Diffuse Idiopathic Skeletal Hyperostosis Resembling Enthesitis of Spondyloarthritis
}

IGNAZIO OLIVIERI, MD, SALVATORE D'ANGELO, MD, Rheumatology Department of Lucania, San Carlo Hospital, Contrada Macchia Romana, 85100 Potenza, Italy; and Madonna delle Grazie Hospital; FRANCESCO BORRACCIA, Researcher, Radiology Department, San Carlo Hospital; ANGELA PADULA, MD, Senior Researcher, Rheumatology Department of Lucania, San Carlo Hospital, and Madonna delle Grazie Hospital, Matera, Italy. Address correspondence to Dr. Olivieri; E-mail: ignazioolivieri@tiscalinet.it. J Rheumatol 2010;37:192-3; doi.10.3899/jrheum.090514

Diffuse idiopathic skeletal hyperostosis (DISH) and ankylosing spondylitis (AS) are 2 clearly different disease entities having in common the involvement of the axial skeleton and the peripheral entheses ${ }^{1,2}$. Both diseases produce bone proliferation in the spine and at the extraspinal entheseal sites in the later phases of their course. Although the aspects of the bone proliferations of the 2 diseases are dissimilar, confusion of radiographic differential diagnosis between the 2 diseases exists, partly as a consequence of a lack of awareness of their respective characteristic features ${ }^{2,3}$. It has been pointed out that the differential diagnosis between DISH and longstanding advanced AS is not limited to the radiologic findings. The determination of which disease the patient has extends to the clinical field since patients with DISH can occasionally have severe limitation of spinal mobility, along with postural abnormalities that resemble longstanding advanced $\mathrm{AS}^{4}$. We describe a case, emphasizing that the clinical differential diagnosis between the 2 diseases is based on peripheral enthesopathy.

The patient, a 48-year-old man, came to us because of postural abnormalities, which at first suggested the diagnosis of longstanding advanced AS, but further evaluation led to the correct diagnosis of DISH. The observation of his heel revealed a diffuse swelling at the insertion of both Achilles

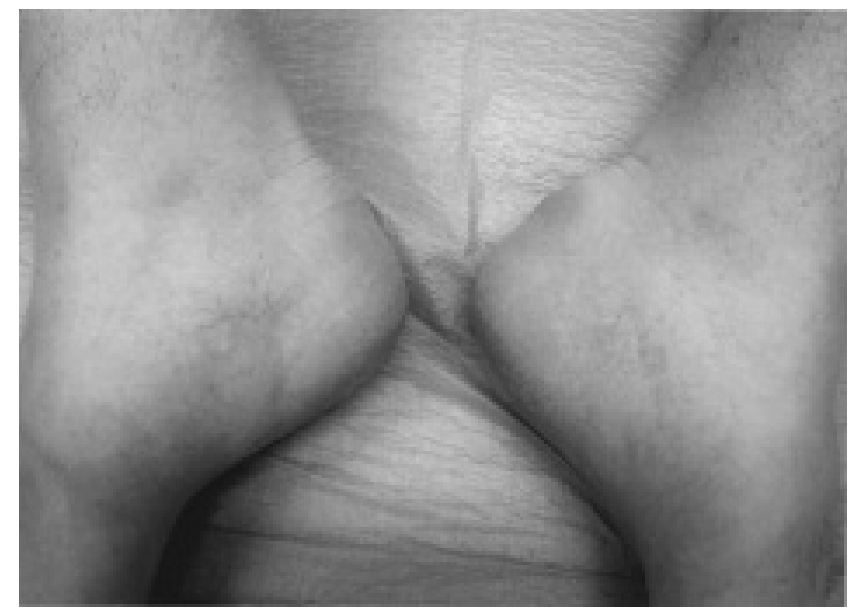

Figure 1. Heel fusiform swelling at the insertion of both Achilles tendons. tendons, resembling the typical fusiform soft tissue swelling of Achilles enthesitis of spondyloarthritis ${ }^{5}$ (Figure 1). However, palpation of the region did not reveal any inflammatory findings of enthesitis but did reveal bone proliferation due to large spurs, a condition confirmed by radiographs (Figure 2). A sacroiliac joint computed tomography (CT) scan showed the normal aspect of joint space and bony margins together with the presence of capsular ossifications (Figure 3).

\section{REFERENCES}

1. Resnick D, Niwayama G. Radiographic and pathologic features of spinal involvement in diffuse idiopathic skeletal hyperostosis (DISH). Radiology 1976;119:559-68.

2. Yagan R, Khan MA. Confusion of roentgenographic differential diagnosis in ankylosing hyperostosis (Forestier's disease) and ankylosing spondylitis. In: Khan MA, editor. Ankylosing spondylitis and related spondyloarthropathies. Spine: State of the art review. Philadelphia: Haley \& Belfus; 1990:561-75.

3. Yagan R, Khan MA. Confusion of roentgenographic differential diagnosis between ankylosing spondylitis (Forestier's disease) and ankylosing spondylitis. Clin Rheumatol 1983;2:285-92.

4. Olivieri I, D’Angelo S, Cutro MS, Padula A, Peruz G, Montaruli $\mathrm{M}$, et al. Diffuse idiopathic skeletal hyperostosis may give the typical postural abnormalities of advanced ankylosing spondylitis. Rheumatology 2007;46:1709-11.

5. Olivieri I, Barozzi L, Padula A, De Matteis M, Pierro A, Cantini F, et al. Retrocalcaneal bursitis in spondyloarthropathy: assessment by ultrasonography and magnetic resonance imaging. J Rheumatol 1998;25:1352-7. 


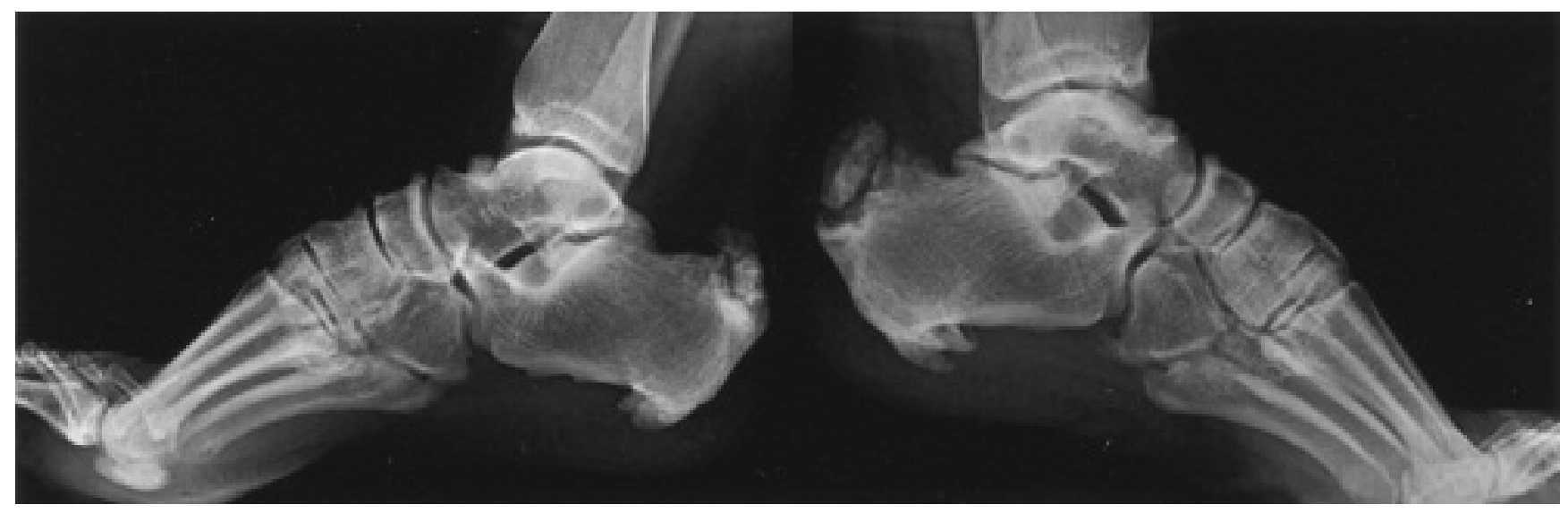

Figure 2. Large bone proliferation at the insertion of both Achilles tendons into calcaneus.

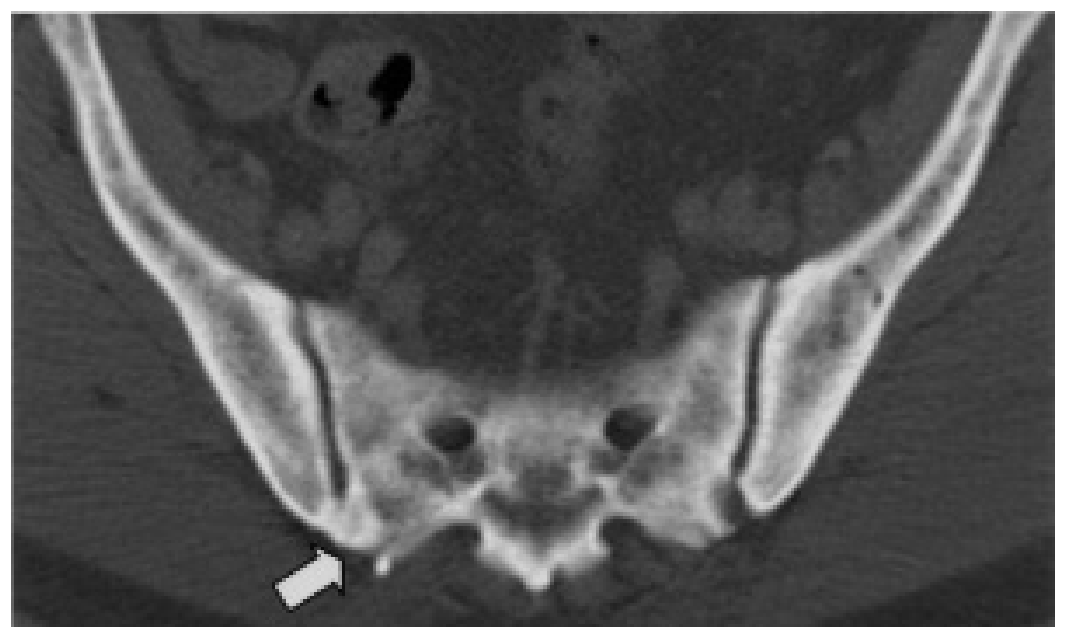

Figure 3. Computed tomography of the sacroiliac joints showing right sacroiliac joint with capsular bridging (arrow) and normal sacroiliac joint configuration with no erosions and bony ankylosis. 